\title{
Effect of Temperature on the Incidence of Cerebro-Spinal Meningitis and Its Management in Funtua Local Government Area, Katsina State, Nigeria
}

\author{
*ALEMAKA, J; SAWA, BA; YUSUF, RO \\ Department of Geography and Environmental management, Faculty of Physical Sciences, Ahmadu Bello University, Zaria, Nigeria \\ *Corresponding Author Email: alemakajohn@yahoo.com,Tel.+234-8025424603; Other Authors Email: senatorsawa@gmail.com; \\ royusuf@abu.edu.ng
}

\begin{abstract}
This study was aimed at analysing the effect of temperature on the incidence of cerebro-spinal meningitis and its management in Funtua General Hospital of Katsina State, Nigeria from 1986-2015. For each year, monthly and annual incidence of CSM occurrence in the study area for the 30 years period was subjected to time series analysis. Linear trend line equation was fitted in order to determine the direction of change in the incidence of CSM. The relationship between temperature and the incidence of meningitis was analysed using simple correlation. To determine the management method of CSM in the area, a questionnaire was used to generate information from sampled respondents and analysed using descriptive statistics. The monthly distribution of CSM cases (1986-2015) indicated April and March had the highest incidence cases (1606 and 1128 respectively) while the lowest cases were recorded in September and October with $(1$ case) each. The seasonal variation also showed that the highest incidence cases fell within the hot-dry season which mark the period with the highest average temperatures while the lowest incidence cases fell within the hot-wet season when humidity is high in the area. Annual trend of CSM indicated an increasing trend (approximately 60 persons) over the 30year period in the study area. There is a significant and positive relationship between mean monthly temperature and incidence of meningitis with an observed value of $(\mathrm{p}<0.05$ and $\mathrm{r}=0.592)$. The observed correlation $(\mathrm{r}=-0.141$, $\mathrm{p}>0.05$ ) indicated that there was negative and insignificant relationship between annual temperature and the incidence of meningitis in the study area. In conclusion, meningitis in the study area over the 30years under review has been a recurrent epidemic however; the rate of occurrence differs from year to year. Majority $(78 \%)$ used the orthodox method to manage CSM while $22 \%$ used the traditional method who claimed it was effective as they recovered from the disease.
\end{abstract}

DOI: https://dx.doi.org/10.4314/jasem.v25i7.29

Copyright: Copyright (C) 2021 Ikoko et al. This is an open access article distributed under the Creative Commons Attribution License (CCL), which permits unrestricted use, distribution, and reproduction in any medium, provided the original work is properly cited.

Dates: Received: 10 May 2021; Revised: 28 June 2021; Accepted: 01 July 2021

Keywords: Temperature, Cerebro spinal Meningitis, Disease Management

Meningitis has been defined as the inflammation of the membrane covering the brain and spinal cord (SaezLlorens and McCracken, 2003). Viruses, bacteria or fungi, certain drugs and diseases such as cancer may cause the inflammation of the meningis (Ginsberg, 2004). Although different infectious agents can cause meningitis, most meningitis cases are caused by meningococcal meningitis and Haemophilus influenza type B (HIB) (Alireza, 2009). It is estimated that roughly, 10 percent of people carry the bacteria in their throat to no ill effect. The bacteria only become a problem when they infect the meningis, the thin lining around the central nervous system.

Meningococcal meningitis has been observed to be a climate sensitive infectious disease. Several studies carried out on the incidence of CSM affirm this fact. Auwal, et al (2014) inferred that future temperature increases due to climate change have the potential to significantly increase meningitis cases in both the early 2025-2035 and late 2060-2075. According to Thigpen (2014) factors that can increase the risk of bacterial meningitis include: age, certain medical conditions, season, and travel among others. Every society makes provision for healthcare delivery system for its people. This is with a view to providing medical and related services for the management of diseases and maintenance of good health. Adefolaju (2014) opined that both traditional and orthodox health systems have been developed to enable the people to meet their health/medical needs. Both systems continue to be patronized by the people depending on their socio-cultural and economic situations. This therefore suggests their functionality and continued relevance to the health needs of the citizens. Preparedness for and management of meningitis epidemic is difficult because vaccines cannot be administered until the different forms of the bacterium spreading are known (UNICEF, 2017). Therefore the present study examined the effect of temperature on the incidence of cerebro-spinal meningitis and its management in Funtua General Hospital in Funtua Local Government Area, Katsina State, Nigeria.

\section{MATERIALS AND METHODS}

The Study Area: The study area is Funtua, Katsina State, Nigeria. It lies between latitude $11^{\circ} 19^{\prime} 59^{/ /} \mathrm{N}$ and 
$11^{\circ} 42^{/} 59^{/ /} \mathrm{N}$, and longitudes $7^{\circ} 14^{/} 59^{/ /} \mathrm{E}$ and $7^{\circ} 29^{/} 59^{/ /} \mathrm{E}$. Funtua is located in the extreme southern part of the state at about $197 \mathrm{~km}$ from Katsina city (the state capital) and $72 \mathrm{~km}$ from Zaria, Kaduna State. It is bordered to the south by Giwa LGA of Kaduna State, to the west by Dandume L.G.A, to the north by Faskari LGA, and to the east by Bakori and Danja LGAs of Katsina State. Funtua Local Government Area covers an area of about $448 \mathrm{~km}^{2}$. The study area is characterized by tropical continental climate (the Koppen's Aw climate, with two well pronounced seasons (wet and dry). However, the two seasons could be further subdivided (based on pronounced temperature variations) into: Warm-dry (Rani in Hausa language) from late February to early April; Warm-wet (Bazare in Hausa) from late April/ early May to late June; Cold-wet (Damina in Hausa) from July to late September/ early October; and Cold-dry (Kaka/ Hunturu in Hausa) lasting from mid-November of one calendar year, mid-February of the next calendar year. The Vegetation of the area is the Sudan Savanna type, which combines the characteristics of both Guinea and Sahel Savanna (Abaje, 2007) as cited in Abaje, Abdullahi and Jeje (2016). The vegetation is composed of numerous short and scattered trees, shrubs and numerous grasses. Common indigenous tree includes silk cotton tree (Ceiba Pentandra), Tamarind tree (Tamarindus indica), Shea-butter tree (Butyrospermum spp.) also known as Kadanya in Hausa, Locust bean tree (Parkia biglobosa) also known as Dorawa in Hausa, Baobab tree (Adansonia digitata), Fan Palm (Hyphaene petersiana) among others. While common grasses in the area include
Gamba grass (Andropogan Gayanus), Signal grass (Bracheria plantaginea), Elephant grass (Pennisetum purpreum), Nigeria grass (Pennisetum pedicellatum), Rhodes grass (Chloris gayana) etc. Some of these vegetal stocks are put together in some of the local herbs used in the treatment of diseases and ailments. For instance it is common for people to use stem, leaves and roots of eucalyptus and magnifera indica to cure fever and similar diseases. Mankade, an oil extract derived from shea butter is used in treating cough and treating cracked heels during the harmattan season. Leaves derived from Mahogany (madachi) and Neem trees are used as local herbs to treat stomach upset and Jaundice (Lawal, 2009). The population of Funtua according to the 2006 Population and Housing Census (PHC) constituted 117,789 males and 107,367 female giving a total of 225,156 . However according to the 2012 estimated census the population of Funtua was 420,110 (PHC, 2010). The inhabitants of the area are predominantly Hausa and Fulani, especially in the rural areas. However, the Urban Funtua is socially heterogeneous with the coming of various ethnic groups such as Yorubas, Igbos, Igalas, Nupe, and Kanuri etc as migrant traders, industrial and public employees. The Hausa and Fulani's are majorly Muslims. Culturally, the male is considered the house hold head that makes most of the decisions influencing the family. Thus decisions on disease management practices are taken by the male. Funtua town is the only urban settlement in the area, while several villages and Hamlets also exist in all directions (Lawal, 2009).

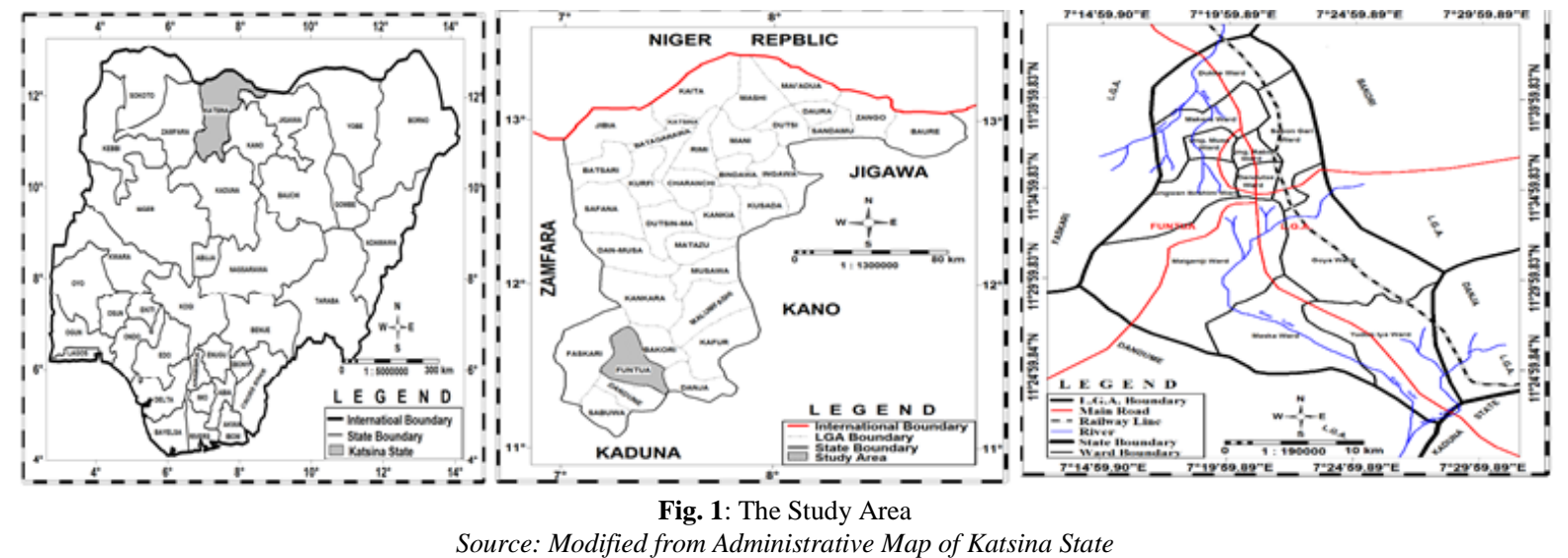

Primary Data: A set of structured questionnaire was used as the main instrument for data collection in this study. The questionnaire consisted of two sections (A and B). Each section had several questions designed to collect relevant information from the sampled respondents.
Secondary Data: Thirty years (1986-2015) hospital records containing the number of cases, age and sex of meningitis patients were sourced from the archive of Funtua General Hospital (Sarkin Maska Shehu Hospital). The choice of this source is based on the fact that it is the largest and only hospital with records on meningitis. The hospital could only make available to 
the researcher records spanning from 1986 to 2015. Records beyond 2015 had not been filtered from the confidential files of patients and that is what informed the period under review. Thirty years (1986-2015) temperature records (maximum and minimum temperatures) for the study area, was sourced from the archive of Katsina state Agricultural and Rural Development Agency, meteorological unit (KATARDA Headquaters).

Methods of Data Analysis and Presentation: To determine the trend of occurrence of meningitis in the study area, the monthly and annual incidence of CSM in the study area for the 30years period was subjected to time series analysis. Linear trend line equation was fitted in order to determine the direction of change in incidence of CSM. The data were analysed with the aid of Microsoft Excel 2013 tool and presented graphically. To determine the relationship between temperature and incidence of meningitis, simple correlation was applied to assess the relationship between the two variables. To examine the management of meningitis in the study area, information on the management methods used by the communities generated from section $\mathrm{B}$ of the questionnaire was analysed using descriptive statistics such as frequency, percentage and mean score and then presented in tables. The mean score $(\bar{x})$ was computed as:

$$
\bar{x}=\frac{1+2+3+4+5}{5}=\frac{15}{5}=3.0
$$

CSM management methods with mean score $<3.0$ were considered as insignificant, while those with mean score $\geq 3.0$ were considered significant.

\section{RESULT AND DISCUSSION}

Temporal Variation of Meningitis: Figure 1 shows the monthly distribution of CSM cases within the years under review. It reveals that the months of April (1606), March (1128) and May (975) have the highest recorded cases respectively. These months coincide with the time of the year when temperatures are at the peak. This period is also characterized by fatigue, dehydration and dryness which increase susceptibility to CSM in the study area (Auwal et al, 2014).

Seasonal variation of Meningitis: The graph in figure 2 shows the seasonal variation of CSM within the period under review in the study area. It reveals that most of the cases start rising from the cold-dry season (Nov-Jan) when the dry harmattan winds adversely affects the respiratory system and creates conditions conducive for the CSM epidemic (WHO, 2012), and attain their peaks in the Hot-dry season ( March/April) when temperatures are on the rise. However, incidence cases begin to drastically reduce during the Hot-wet season (May-July) and during the cold-wet season (Aug-Oct) when the lowest incidence cases are recorded (1 case in Sept and Oct each) due to increase in humidity. Incidence cases gradually start to rise in November which marks the onset of the cold-dry season. This affirms the work of Jandarov et al (2012).

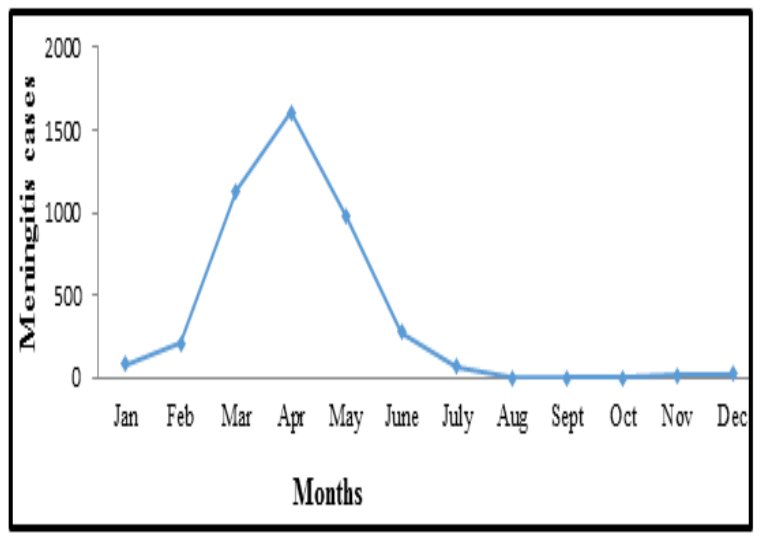

Fig 1. Monthly Distribution of CSM

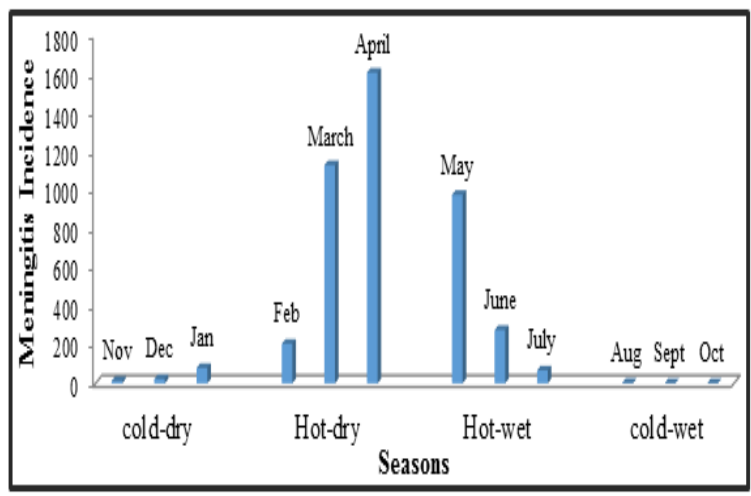

Fig 2: Seasonal variation of Meningitis incidence

Annual Trend of CSM: A close look at the linear trend in figure 3 reveals an increasing trend in the incidence of meningitis at the rate of approximately two (2) persons per annum over the 30 years period in the study area. It also indicates that the year 2000 had the highest incidence of 321 cases (7\%); followed by year 2010 with 260 cases (6\%) and 1997 with an incidence rate of 246 cases $(5.2 \%)$. However, the year 2001 has the lowest incidence of the epidemic (20 cases). A closer examination of the trend shows that, a total positive change of approximately 60 persons were observed over the 30 year period. The linear trend indicates an increase in the incidence of meningitis in the study area. The result of the test reveals that mean monthly temperature is a significant factor in the incidence of meningitis over the 30 year period. With $r=0.593$ indicates that there is a positive and strong 
relationship between the two variables and with a $\mathrm{P}$ (0.043) value which is $<0.05$ implies that the variables are significantly related. That means mean monthly temperature has a strong influence on the incidence of meningitis in the study area

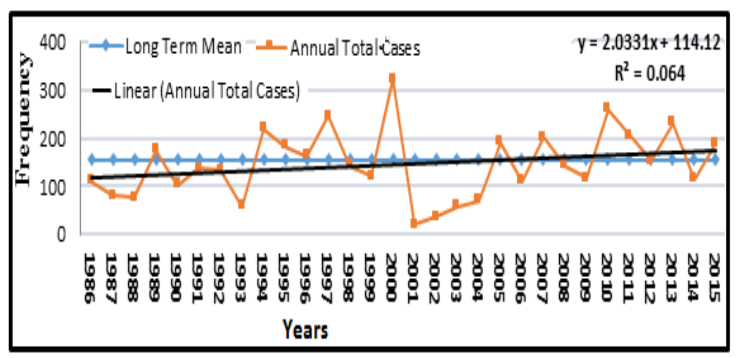

Fig 3. Annual Trend of CSM Incidence in Funtua LGA

Table 1. Relationship between Mean Monthly Temperature and Incidence of Meningitis

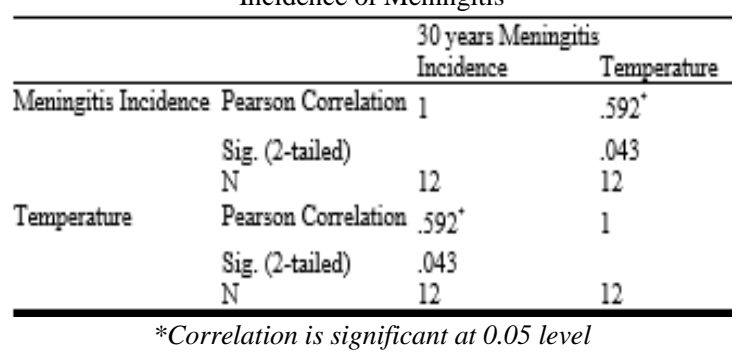

Table 2: Relationship between Mean Annual Temperature and Meningitis

\begin{tabular}{|c|c|c|c|}
\hline \multirow{4}{*}{ Temperature } & & \multicolumn{2}{|c|}{ Temperature Incidence of meningitis } \\
\hline & Pearson Conrelation & 1 & -.141 \\
\hline & Sig. (2-tailed) & & .456 \\
\hline & & 30 & 30 \\
\hline \multirow[t]{3}{*}{ Incidence of meningitis } & Pearson Correlation & -.141 & 1 \\
\hline & Sig. (2-tailed) & .456 & \\
\hline & $\mathrm{N}$ & 30 & 30 \\
\hline
\end{tabular}

Table 2 shows the relationship between mean annual temperature and the incidence of meningitis. The observed correlation $(r=-0.141)$ implies a negative and weak relationship between mean annual temperature and incidence of meningitis in the study area. With a $p$ (.456) value which is $>0.05$ indicates that there is no significant relationship between annual temperature and the incidence of meningitis in the study area over the 30-year period. This implies that, mean annual temperature might not be the only controlling factor on the inter-annual incidence of CSM in the study area. There is the possibility of having some years with wetter, rainy season lasting longer than usual hence reducing the overall effect of three decades temperature on meningitis.

Method of CSM management: Figure 5 shows that majority (78\%) of the respondents used the orthodox method to manage meningitis while $22 \%$ used the traditional method. This is attributed to the aggressive campaigns by the ministry of health through the Public Health Services department who move from one community to another to collaborate with Local Government Authorities and village heads to educate and sensitize the people on the advantages of orthodox medicine in combating diseases such as polio, meningitis, measles and other diseases that usually breakout from time to time.

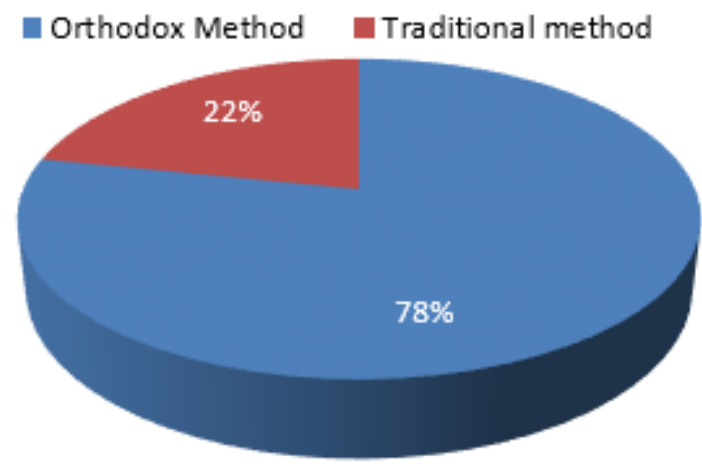

Fig 5. Method CSM Management Method Adopted by the Respondents

Effectiveness of meningitis management method: Respondents in the study area either adopted the orthodox or traditional method to manage CSM. The method adopted is based on which method each respondent perceives to be the most effective. Table 3 presents the perceived effectiveness of both the orthodox and traditional methods of managing meningitis.

Table 3 Perceived Effectiveness of Methods Adopted to Manage

\begin{tabular}{lll}
\multicolumn{3}{c}{ Meningitis } \\
\hline S/NO & Method Adopted & Mean Score \\
\hline 1 & Othodox Method & $3.4^{*}$ \\
2 & Traditional Method & 1.0 \\
*Significantly Perceived Effective Method among Respondents in & the Study Area
\end{tabular}

The result in Table 3 shows that the Orthodox method of managing CSM among the respondent is the most adopted method with a mean score of 3.4 which is > 3.0. The traditional method on the other hand was less adopted among the respondents.

Effectiveness of Orthodox management Method: The respondents that adopted the orthodox method of managing meningitis gave varying opinions on the effectiveness of the method depending on their experiences as shown on figure 6. On aggregate $81 \%$ considered the orthodox method to be effective while $19 \%$ felt it was ineffective because the patients they took to the hospital did not survive. Further inquiry revealed that those who considered the orthodox method ineffective did not take the patients to the 
hospital on time because they initially thought it was fever and therefore resorted to self-medication at the initial stage. Besides, the researcher also observed that those that lost their loved ones lived in very poorly ventilated apartments. This could have been responsible for the deaths.

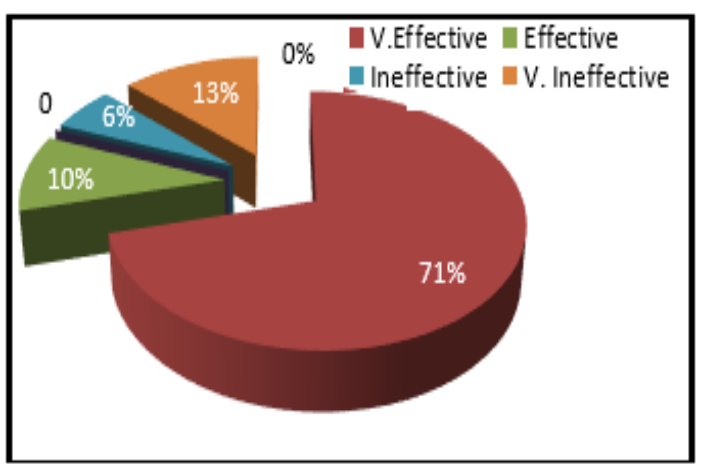

Fig 6: Effectiveness of the Orthodox method of CSM Management among Respondents

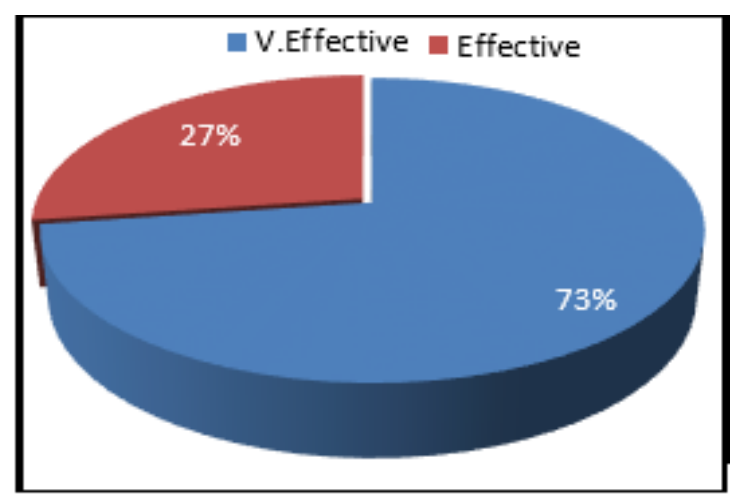

Fig 7 Effectiveness of the Traditional Method

Effectiveness of the Traditional Method: Figure 7 shows that all the respondents that adopted the traditional method considered it to be effective as they all claimed that they fully recovered from CSM. To be sure if they knew the symptoms of meningitis, the researcher asked the respondents to enumerate the symptoms which they did accurately.

The respondents enumerated the following herbs as what was administered to manage meningitis: Marke (Aogeissus Leiocarpus), Zaitun (OleoEnropea also known as Olive plant), Kalgo (Piliostigma Recticulatum), and Magaryaa (Ziziphus Abyssinica). Some of the herbs mentioned above affirm the work of Whitsitt (2014) who is also an advocate for the use of herbs and mentioned the Olive plant as a herb for treating CSM instead of antibiotics which come with their side effects.

Respondents Acceptance of Vaccination: The respondents in the study area held varying views on vaccination which influenced the level of acceptance. Analysis reveals that $65 \%$ (249) of the respondents and their households have had vaccination against CSM, while 35\% (134) of the respondents have never had vaccination against CSM. Those who have never had vaccination against meningitis gave their reasons ranging from preference for traditional medicine, not being aware of it, lack of trust in vaccines and not taking vaccine because they don't feel sick.

Conclusion: The positive relationship between mean monthly temperatures and the incidence of Meningitis, with highest cases recorded in the hot-dry season, indicates the effect temperature has on human health. Thus, it can be concluded that with the unprecedented increase in global average temperatures (global warming) in recent decades, meningitis cases will continue to rise just as the annual trend analysis indicates meningitis is increasing in the study area. It can also be inferred that the traditional method of managing meningitis is very much in existence thus, the efficacy of these herbs should be verified.

\section{REFERENCES}

ABAJE, IB (2007). Introduction to Soils and Vegetation. Kafanchan Personal Touch Productions Limited, Kafanchan, Kaduna State, Nigeria. Pp 97-108.

ABAJE, IB; ABDULLAHI, N; JEJE, OG (2016). Climate Change and Infectious Diseases in Funtua Local Government Area of Katsina State, Nigeria. Afr. J. Online, 5 (1): 047-050.

ADEFOLAJU, T (2014). Traditional and Orthodox Medical Systems in Nigeria: The Imperative of a Synthesis. Amer. J. Hlth. Rsrch. 2 (4): 118-124

ALIREZA, M (2009). Temporal Analysis of the Incidence of Meningitis in the Tehran Metropolitan Area 1999-2005. Published 2009; license BioMed Central Ltd. http://creativecommons.org/licenses.

AUWAL, F; ANDREW, JM VANJA, MD; MARY, HH; GEORGE, CL; JONES, ET (2014). The Impact of Climate Change on Meningitis in Northwest Nigeria. An Assessment Using CMIDS Climate model Simulations. AMS. J. volume 6. Retrieved from journals.ametsoc.org at $3: 25 \mathrm{pm}, 24 / 11 / 2015$

GINSBERG, L (2004). Difficult and Recurrent Meningitis. J. Neurol, Neurosurg and Psych. 75 suppl 1(90001):1621, PMC 176549. 
JANDAROVE, R; HARAN, M; and FERRARI, M (2012). A Compartmental Model for Meningitis Separating Transmission from Climate Effects on Disease Incidence. J. Agric. Biol Environ. Stat., 17, 395- 416

LAWAL, IM (2009). Funtua A History of Maska and Funtua Districts. Kano, Alfikra Publication Ventures. Nigeria Limited.

Population and Housing Census (2010). Priority table volume III. Retrieved from www.population.gov.ng.

SAEZ-LLORENSE, X; McCracken, GH (2003). Bacterial Meningitis in Children. Lancet. 361(9375): 2139-48. PMID 12826449.
THIGPEN, MC. (2014). Bacterial Meningitis in the United States, 1998-2007. Retrieved from www.gov/meningitis at $6: 14 \mathrm{pm}$ on $26 / 11 / 2016$.

UNICEF (2017): West Africa on Alert for Meningitis Epidemic. www.unicef.org. $7^{\text {th }}$ Nov 2017

WHITSITT, k (2014). Meningitis Treatment: Traditional Medicine Versus Alternative Ideas. Ezine Articles. www.ezinearticles.com.

World Health Organization (2012): Meningococcal Meningitis. Retrieved from www.who.int/medicenter/factsheet. 